\title{
Classification and Identification of Urban Forest Soundscapes (Study of the Reached Green Open Space Standard)
}

\author{
Lailatul Inayah \\ Departemen of Physics Institut \\ Teknologi Sepuluh nopember \\ Surabaya, Indonesia \\ lailinayah94@gmail.com
}

\author{
Suyatno \\ Departemen of Physics Institut \\ Teknologi Sepuluh nopember \\ Surabaya, Indonesia \\ kangyatno@physics.its.ac.id
}

\author{
Susilo Indrawati \\ Departemen of Physics Institut \\ Teknologi Sepuluh nopember \\ Surabaya, Indonesia \\ susilo.indra@physics.its.ac.i
}

\begin{abstract}
An urban forest is part of green open space, which has aesthetic and social functions in an urban area. Urban forests cannot be separated from the problem of noise caused by diverse urban activities. Of course, this causes a shift in the function of urban forests as a whole. A sound composition that occurs and interacts with certain landscapes called the soundscapes. This study aims to classify the soundscapes in urban forests based on the perception of an acoustic environment and identify the soundscapes in urban forests based on environmental acoustic parameters. In this study, the soundscapes framework analyzed by using the Kano Model refers to ISO Soundscapes 12913-1-2014. In this framework, evaluate the soundscapes approach using objective parameters and factors that influence positive perspectives on the soundscapes. Classification of soundscapes done through questionnaires processed with Agglomerative Hierarchy Clustering. Then, identified each cluster by using the measurement of objective acoustic parameters. Identification also carried out the soundwalk. The parameters used are L10, L93, Lmax, LEq, $\tau 1, \Phi 1$, and DR. Based on the results of the study, the soundscapes can be classified into three groups, namely, the dominance of traffic, natural and human sounds, and human sounds. This can be explained physically through several predetermined parameters. Based on the results of the study, the soundscapes can be classified into three groups, namely, traffic dominance, natural and human sounds, and human sounds. The results of the soundscapes identification on Route show the natural sounds (wind and bird chirps) expressed by values Leq=57.24 $\mathrm{dBA}, L 10=59.13 \mathrm{dBA}$, $L 93=54.52 \mathrm{dBA}, \mathrm{Lmax}=63.41 \mathrm{dBA}, \tau 1=2.97 \mathrm{~s}$, dan $\Phi 1=0.3$ $\mathrm{DR}=9.6 \mathrm{~dB}$. Also, identification using a spectrogram shows the dominance of wind and birds chirping on this route.
\end{abstract}

Keywords: classification, green open space standard, identification, soundscapes, urban forest

\section{INTRODUCTION}

Noise defined as unwanted sounds from certain activities and potentially causing hearing loss. Meanwhile, the sound is defined as varying pressure that propagates in the medium so that it reaches the human ear [1]. In urban areas, one of the causes of noise is activities, such as traffic, industry, offices, and so on. Noise can have a negative influence on human health and activity. The higher the noise level, the greater the risk of hearing loss and stress [2]. One of the noise control efforts can be using a barrier in the form of vegetation in the urban landscape. In addition to functioning as an aesthetic enhancer, and temperature control, vegetation with various strata and density structures has a good role in reducing noise. This space plays a role in aesthetic functions and social functions in an urban area. Fulfillment of RTH as a function that represented in several parameters that can be quantized, one of which is noise. KEP-48 / MENLH / 11/1996 regulates noise thresholds in various places as follows.

TABLE 1 NOISE THRESHOLD VALUE

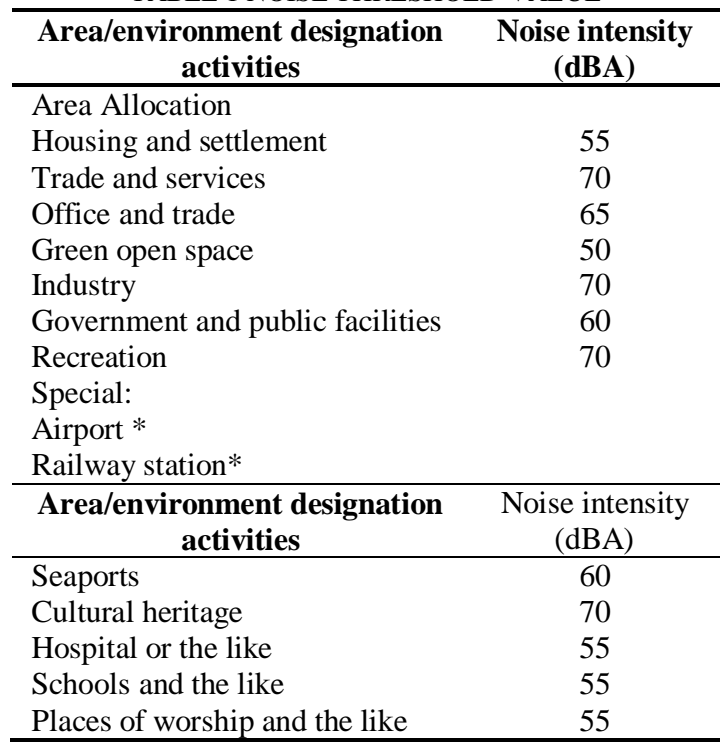

Refers to Table 1, the standard noise level of RTH is $50 \mathrm{dBA}$. To carry out noise control, it needs to be analyzed in terms of environmental acoustics, both objectively and subjectively. The analysis integrates the environment acoustic call is soundscapes. The soundscapes are used to describe the interaction of landscape and sound composition. A person's perception of the soundscapes blends with the environment he occupies. So, he was able 
to describe the state of the environment through several physical attributes. Thus, perceptions of the environment of acoustic can be measure as physical [3]. The parameters that must be measured are sound patterns are temporal patterns, spatial patterns, and interactions [4]. The function of the objective parameter is to represent the character given by the source. The parameter in question is the temporal sound level. Figure 1 shows the shape of the sound signal as a function of time.

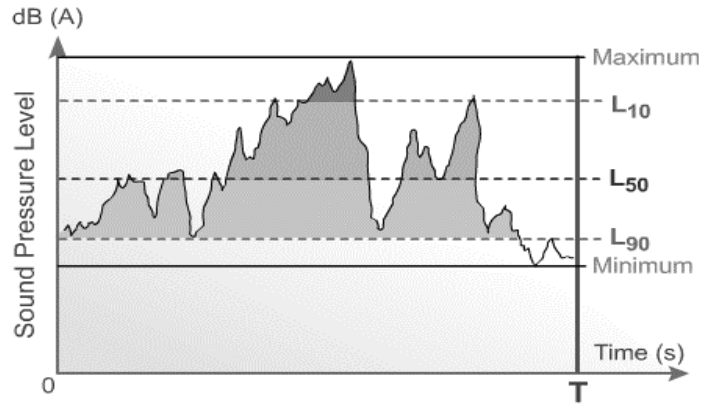

Fig. 1 Temporal sound level (Environmental Protection Department)

Based on Fig. 1, the temporal of the sound level consists of $\mathrm{L}_{\min }, \mathrm{L}_{\max }, \mathrm{L}_{10}, \mathrm{~L}_{50}, \mathrm{~L}_{90}$, dan $\mathrm{L}_{\text {eq }}$. Physically, $\mathrm{L}_{10}$ is the noise level, which is included in $10 \%$ of the measurement time and is said to be the loudest so this parameter is called peak noise. $\mathrm{L}_{50}$ is the noise level that covers $50 \%$ of the measurement time or called the Mean Noise Level. $\mathrm{L}_{90}$ is the noise level includes $90 \%$ of the measurement time and can represent the background noise. [5]. Meanwhile, $\mathrm{L}_{\mathrm{eq}}$ is the noise level, which for a certain period has the same amount of sound energy as the fluctuating sound source level

In addition to these parameters, it is necessary to quantify the human perspective or subjectivity that can be formulated by using physical parameters. One of them is using the ACF (autocorrelation function). The formula of ACF are as follows in Eq.(1),

$$
\varphi 11 \tau=\varphi 11 \tau \varphi 110
$$

Based on Eq.(1), $\tau_{1}$ defined as the first delay time, and $\Phi_{1}$ defined as the first peak amplitude. Both of these parameters are related to the sensation and strength of the perceived pitch of complex sounds. ACF is obtained from the geometric mean of energy at the time $s$ and $s+\tau$. So $0 \leq \varphi 11 \tau \geq 1$. ACF gives a physical meaning that, the higher it is $\Phi(\tau)$, the pitch gets stronger and the higher it is $\tau$, the pitch gets lower [5].

The other parameter used is $D_{R}$ (Dynamic Range). These parameters represent the maximum difference from SPL $\left(\mathrm{L}_{\max }-\mathrm{L}_{\min }\right)$. Parameter $\mathrm{D}_{\mathrm{R}}$ is used to identification of fluctuating sound signals and to predict the perception of the urban soundscapes [6]. Related to the category of accepting subjects for sound level changes can be seen in Table 2.

TABLE 2 SUBJECTIVE ASSESSMENT TO SOUND LEVEL'S CHANGE

\begin{tabular}{cc}
\hline Sound level change $(\mathrm{dB})$ & Subject assessment \\
\hline 6 & Barely perceptible \\
10 & Clear perceptible \\
20 & Twice/half as loud \\
40 & Very loud \\
\hline
\end{tabular}

Table 2 explains that subject acceptance is influenced by changes in sound level. The greater the level of sound change, the higher the subject perceived more clearly. This also applies to $D_{R}$ that is used to predict subjective perceptions of the soundscapes.

In this study, classification and identification of soundscapes were carried out based on the standard quality of green open spaces on several routes and measurement times. The purpose of classification is to simplify the steps in evaluating and handling noise that occurs in urban forests. Classification is done by Agglomerative Hierarchy Clustering. The classification results obtained were identified by objective parameters (temporal level) and subjective (ACF and $D_{R}$ ) to explain the sound characteristics of each cluster based on their level, frequency content, and dynamics. These parameters can be used to predict how an individual's perspective with soundscapes is. The location chosen is Joyoboyo Forest, Kediri City. In part, II explained the methodology in researching to achieve goals, part III about the results and discussion and in section IV contains conclusions.

\section{METHOD}

\section{A. Framework}

The Joyoboyo Forest soundscapes framework was compiled using the Kano Model based on ISO Soundscapes 12913-1-2014. This modeling was chosen because it is suitable for use in urban public space, which is often interpreted negatively or considered as noise. In this modeling, an approach to sound composition carried out given objective parameters and factors that influence an individual's perspective on the soundscapes [8]. The framework in question can be seen in Fig. 2 below.

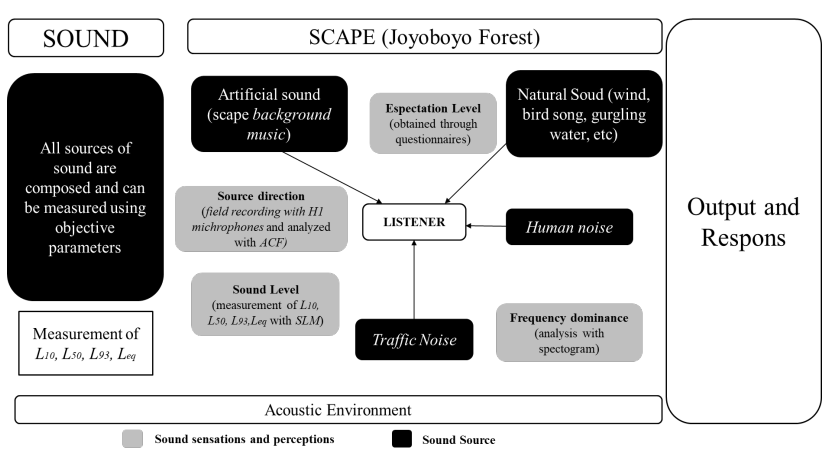

Fig. 2 Joyobo Forest soundscapes framework

Fig.2 explains the soundscapes framework with sound composition consists of traffic noise, natural sounds, artificial sounds, and human sounds that are composed in Joyoboyo Forest as an urban landscape. The sound composition will interact between the environment and an acoustic environment that cause sensations when heard by visitors to the Joyoboyo Forest. This sensation will give rise to certain perceptions of the existing acoustic environment, so encouraging visitors to respond. Factors that influence subjects such as sound dominance, sound direction, and dominant frequency perceptions can be measured using physical quantities in environmental acoustics. 


\section{B. Measurement}

Spectral patterns, temporal patterns, and spatial patterns on soundscapes can be obtained by measuring the environmental acoustic parameters consisting of subjective parameters and objective parameters. Subjective parameters are used to determine the quality of the soundscape based on individual perspectives. These parameters represent the quality of the Joyoboyo forest soundscapes. The Soundscapes measurements are done by the soundwalk method. This method is a data retrieval technique that carried out while enjoying the sound at Joyoboyo forests. Caused by the very wide research location, so the soundwalk divided into several routes shown in Fig. 3 below.

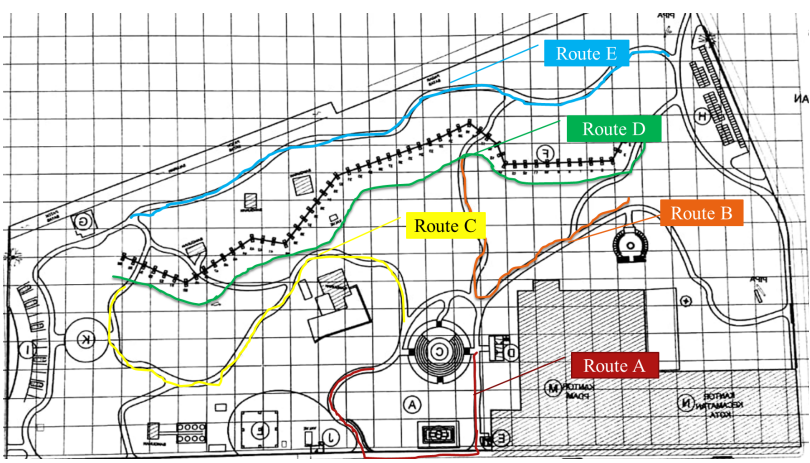

Fig. 3 Route of soundwalk

Based on Fig.3, the soundscapes measurement with the soundwalk is carried out on 5 routes. The measurement divided into several sessions, namely session I, session II, and session III. The selection of the measurement session done as time sampling so that the results could represent fluctuating valuation objects obtained. Measurement of objective parameters when the soundwalk performed on $\mathrm{L}_{10}, \mathrm{~L}_{90}, \mathrm{~L}_{\max }, \mathrm{L}_{\min }$, and $\mathrm{L}_{\mathrm{Eq}}$ with the duration of data retrieval for 10 seconds. This was done as proposed by ISO 1996-1: 2016 by using Sound Level Meter Rion NL 21. These parameters describe the Sound Pressure Level (SPL). Besides, these parameters can also be used in the analysis of temporal patterns from environmental acoustics. The configuration of objective parameter measurements designed as shown in Fig.3.

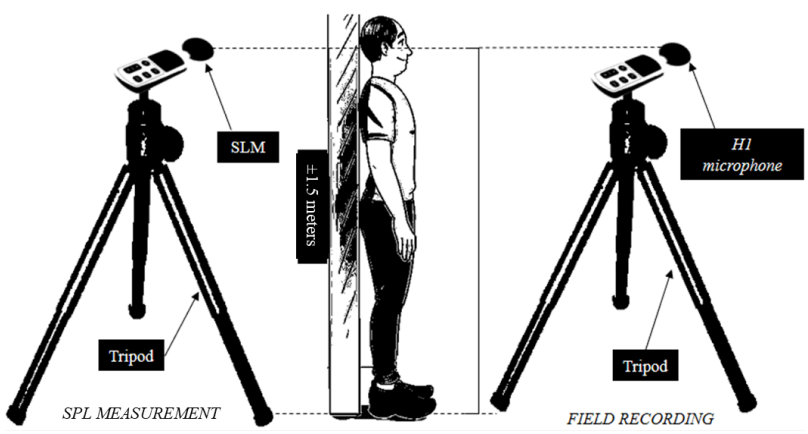

Fig. 4 Configuration of objective measurement

The measurement configuration carried out in Fig. 4 refers to ISO1996/1 Acoustics-Description, measurement, and assessment of environmental noise - Part 1: Basic quantities and assessment. In general, measurements using a Sound Level Meter that adjusted to the height of the human ear with the A-weighting filter (dBA) [9]. The $\mathrm{ACF}$ analysis is done through field recording from the soundwalk method using the H1 microphone with a position that is identical to the human ear. Furthermore, the results of the recording are processed and calculations performed using Realtime Analyzer and Sound Analyzing System. The ACF in the soundscapes contains psychoacoustic elements used in evaluating sound quality especially based on the standard of green open space. While $D_{R}$ can be obtained from the difference between $\mathrm{L}_{\max }$ and $\mathrm{L}_{\min }$ to find out the sound dynamics.

Subjective soundscapes measurements in this study conducted by the questionnaire method. This method aims to quantify the qualitative soundscapes parameters. This method involved 35 respondents to assess the field recording results from the $\mathrm{H} 1$ microphone. The recording field is nothing but a recording obtained during the soundwalk. Questionnaires carried out as a subjective evaluation of the Forest Joyoboyo soundscapes based on respondents' perspectives with the following attributes in TABLE 3.

TABLE 3 SOUNDSCAPES ATTRIBUTE ASSESSMENT

\begin{tabular}{cc}
\hline Acoustics Attribute & Visual Attribute \\
\hline Refreshing & Bright \\
Hustle and bustle & Open \\
Crowded & Clean \\
Comfortable & Monotonous \\
\hline
\end{tabular}

TABLE 3 contains the parameters used in the questionnaire and is presented using the semantic scale. Soundscapes measurements performed on 5 routes and 3 sessions certainly produce a lot of data and cause difficulties in identifying and analyzing. This problem can be simplified by using grouping data in several parts. Then it can be done by cluster analysis, which is a multivariate statistical method that aims to group objects in several groups based on their characteristics. In this study, cluster analysis carried out to classify routes in Joyoboyo Forest based on the ratings given by respondents. The assessment carried out on the quality of the soundscape carried out through questionnaires. The type of cluster analysis performed is Agglomerative Hierarchical Clustering with a single linkage approach. Cluster analysis performed with Microsoft Excel 2016 and SPSS 17 software.

In addition to cluster analysis, comparison tests also used to determine the soundscapes that the subject most likes based on the measurement route. This method is a psychoacoustic test performed by selecting one of the preferred pairs of sounds. Through this method, you can find out the most preferred sound by the respondent, which is the sound that has the highest score. The sound source tested came from the Lenovo IP-330 PC and respondents listened with Sennheiser headphone aids

\section{RESULTS AND DISCUSSION}

\section{A. Objective Identification}

As stated in section I, criteria from the soundscapes include objective and subjective parameters. Soundscapes measurements are performed by the soundwalk method on the following route in Fig.5. 


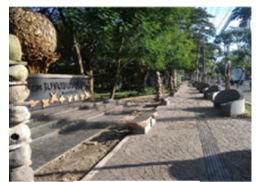

(a) Route $\mathrm{A}$

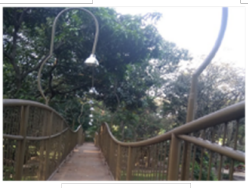

(d) Route D

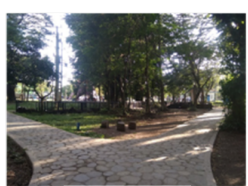

(b) Route B

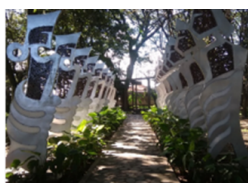

(c) Route C

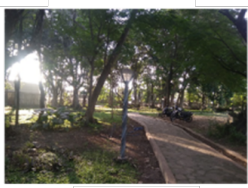

(e) Route E

Fig. 5 Route of soundwalk (a) Route A (b) Route B (c) Route C (d) Route D (e) Route E (source: private document)

Measurement of objective parameters includes $\mathrm{L}_{\text {Aeq }}$, $\mathrm{L}_{\mathrm{A} 10}, \mathrm{~L}_{\mathrm{A} 93}$, and $\mathrm{L}_{\mathrm{Amax}}$ performed on five routes in three sessions using the soundwalk method. Based on Figure 5, route A is located closest to the highway. In the route, there are amphitheater and Tugu Joyoboyo, as locations that are more frequently visited by visitors. Furthermore, routes $\mathrm{B}$ and $\mathrm{C}$ are located in the middle part of Joyoboyo Forest, while route $\mathrm{D}$ is in the form of a sky bridge located at the back of Joyoboyo Forest at an altitude of \pm 5 meters. Route E is located at the very back and there is a playground in it. The timing of measurements based on a time zone that can represent the soundscapes characteristics in Joyoboyo Forest as a whole. Thus, three sessions measurement, namely session I (08.30-09.30 am) represent with less crowded traffic and quite crowded visitors, session II (01.00-02.00 pm) representing with visitors who relatively rare and traffic is not too crowded, and session III (04.00-05.00 pm) represents with many visitors and busy traffic at work hours. The measurement results show varying values. The measurement results obtained shown in TABLE 4 below.

TABLE 4 Results of measurements of environmental acoustic parameters

\begin{tabular}{cccccc}
\hline Route & $\begin{array}{c}\text { Measurement } \\
\text { Session }\end{array}$ & $\begin{array}{c}\mathrm{L}_{\text {Aeq }} \\
(\mathrm{dBA})\end{array}$ & $\begin{array}{c}\mathrm{L}_{\mathrm{A} 10} \\
(\mathrm{dBA})\end{array}$ & $\begin{array}{c}\mathrm{L}_{\mathrm{A} 93} \\
(\mathrm{dBA})\end{array}$ & $\begin{array}{c}\mathrm{L}_{\text {Amax }} \\
(\mathrm{dBA})\end{array}$ \\
\hline A & & 67.48 & 69.63 & 64.79 & 72.46 \\
B & Session I & 61.15 & 63.44 & 57.96 & 66.35 \\
C & $(08.30-09.30$ & 62.96 & 64.42 & 61.05 & 66.76 \\
D & am $)$ & 61.01 & 63.56 & 56.97 & 66.87 \\
E & & 57.17 & 59.28 & 54.49 & 62.71 \\
\hline A & & 61.88 & 63.42 & 59.81 & 66.31 \\
B & Session II & 54.88 & 56.15 & 53.16 & 60.04 \\
C & $(01.00-02.00$ & 59.09 & 60.21 & 57.72 & 63.78 \\
D & pm) & 56.69 & 58.07 & 54.71 & 63.06 \\
E & & 54.88 & 56.71 & 52.20 & 61.98 \\
\hline A & & 62.87 & 64.35 & 60.93 & 68.14 \\
B & Session III & 57.79 & 59.86 & 54.76 & 64.48 \\
C & $(04.00-05.00$ & 58.08 & 59.77 & 55.70 & 63.26 \\
D & am $)$ & 57.24 & 59.13 & 54.52 & 63.41 \\
E & & 55.71 & 58.14 & 52.28 & 62.18 \\
\hline
\end{tabular}

Based on TABLE 4, all of the measurement results show a sound level that exceeds the green open space noise threshold of $50 \mathrm{dBA}$. Based on $\mathrm{L}_{\mathrm{Aeq}}$ measurements in all sessions, Route A has a higher sound level than the other routes. This caused by the location of Route $A$ that is

adjacent to the dominant source, namely traffic noise. Further, this can be reviewed through the $\mathrm{L}_{\mathrm{A} 10}$ (peak noise) parameter. This parameter can show the level of traffic noise is on Route $\mathrm{A}$ and other routes. While background noise is shown by the $\mathrm{L}_{\mathrm{A} 93}$ parameter. the frequency content and the type of sound can be presented in the following spectrogram.
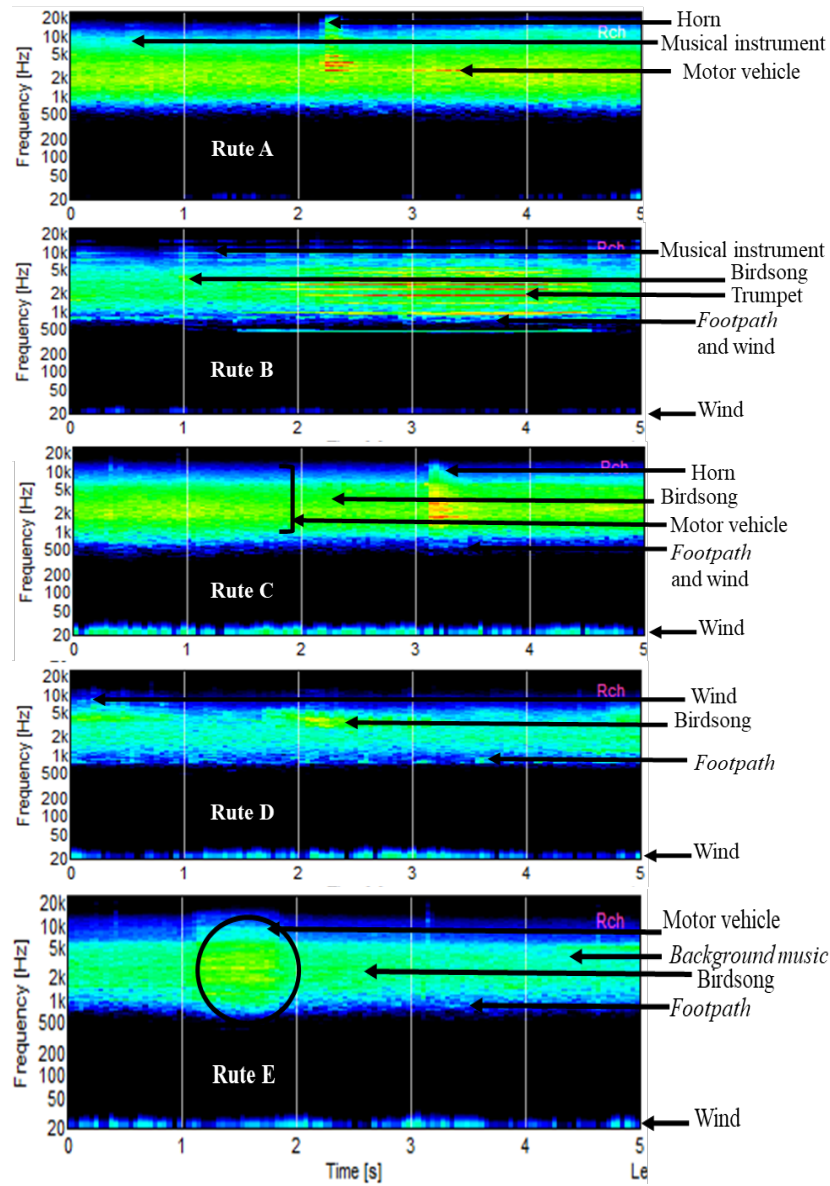

Fig. 6 Soundscapes spectrogram for each route

The other parameters to judge the sound can predict by ACF. Figure 7 shown the ACF parameters of the soundscapes.

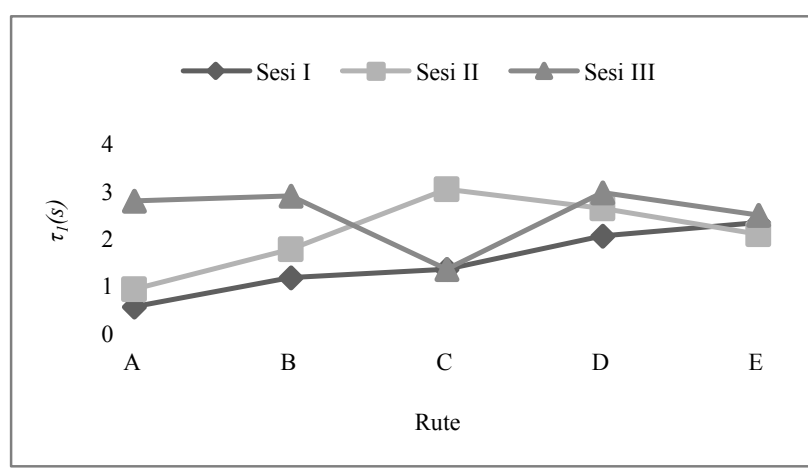

Fig. 7 Parameter $\tau 1$ on each route 


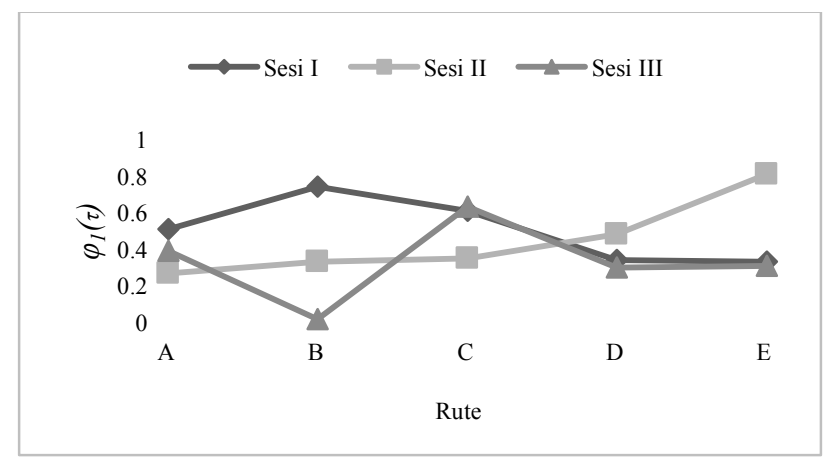

Fig. 8 Parameter $\Phi 1$ on each route

Based on Fig.7, routes $\mathrm{A}$ and $\mathrm{C}$ have lower $\tau_{1}$ than another route, then both routes have a relatively shorter delay and have a higher pitch with more frequency content. Base on the spectrogram in Fig. 6 that on routes A and $\mathrm{C}$ there are high frequencies with high levels produced by horn sounds. Routes B, D, and E pitch are lower with the dominance of wind sounds and birds singing. Meanwhile, if reviewed with parameter $\Phi_{1}$, route $B$ has a higher value than other routes and at the same time explains that the route has the loudest pitch that comes from the sound of the trumpet as shown in Fig.6. Overall, the measurable parameter $\Phi_{1}$ in Fig. 8 shows that the sound signal is not completely identical (the signal received by the right ear is not the same as the signal received by the left ear) with a certain coefficient value. The positive value of $\Phi 1$ indicates the coming of the sound source from the right. The direction is the position of the dominant sound source, namely traffic on the one-way road that passes from right to left to the position of the $\mathrm{H} 1$ microphone. The greater of $D_{R}$ value means the more dynamic of the sound. Large changes in sound level will affect subjective acceptance. Figure 8 shows the $D_{R}$ values of the five-soundscapes routes in the Joyoboyo Forest of Kediri City.

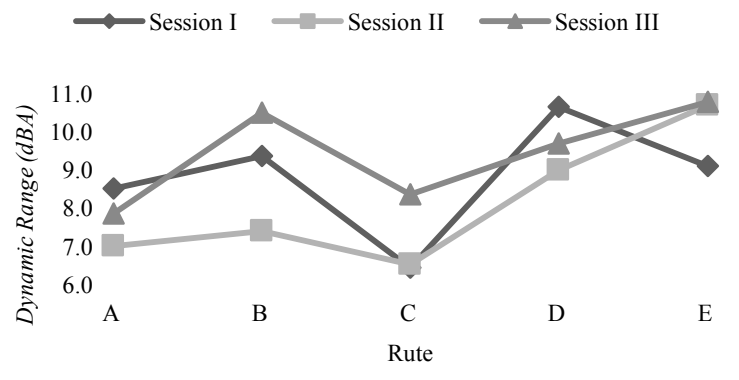

Fig. 9 Calculation result of DR

Based on Fig.8, the dynamic range of sound was measured is levels 6 to $11 \mathrm{dBA}$. If viewed from the subjective acceptance, sound changes of $6 \mathrm{dBA}$ are still not felt. The change can only be the felt site at a minimum level of $10 \mathrm{dBA}$. High dynamic ranges caused by temporal sounds, generated by various sources and various frequency content. This can be seen on route $\mathrm{D}$ dominated by birds, winds and other sounds. Whereas the continuous sound shows a relatively lower dynamic range, such as Route A with a single dominance by continuous traffic noise and monotonous.

\section{B. Cluster Analysis}

Cluster analysis in this study used to classify location points in Joyoboyo Forest based on the soundscapes' characteristics. The classification aims to facilitate and simplify the problem of the soundscapes. So, improvement and repair of a more effective and efficient quality of the soundscape using binaural tets on 35 respondents. The sample consisted of routes $\mathrm{A}, \mathrm{B}$, and $\mathrm{D}$ in three measurement sessions, so that the total number of test samples was 9. At this stage, routes $\mathrm{C}$ and $\mathrm{E}$ eliminated from binaural tests and comparison tests among the routes. The character of route $\mathrm{C}$ has similarities to route $\mathrm{A}$ that dominated by traffic noise. The character of route $\mathrm{E}$ has similarities with route $\mathrm{D}$ which is dominated by natural sounds. Cluster analysis performed in this study refers to the classification of city park soundscapes based on perceptions performed by Jin Yong Jeon and Joo Young Hong (2015). Cluster analysis carried out using the Single Linkage HCA (Hierarchical Cluster Analysis) method into three clusters.

\begin{tabular}{|c|c|c|c|c|c|c|}
\hline Cluster & Route & $\begin{array}{c}\mathrm{L}_{\mathrm{eq}} \\
(\mathrm{dBA})\end{array}$ & $\tau_{1}(\mathrm{~s})$ & $\Phi_{1}$ & $\begin{array}{c}\mathrm{D}_{\mathrm{R}} \\
(\mathrm{dBA})\end{array}$ & $\begin{array}{c}\text { Dominant } \\
\text { Frequency } \\
\text { Content } \\
\end{array}$ \\
\hline \multirow{3}{*}{1} & A 1 & 67.48 & 0.57 & 0.51 & 8.5 & $\begin{array}{c}\text { Traffic } \\
\text { noise }\end{array}$ \\
\hline & A2 & 61.88 & 0.93 & 0.27 & 6.9 & $\begin{array}{c}\text { Traffic } \\
\text { noise }\end{array}$ \\
\hline & A3 & 62.87 & 2.79 & 0.39 & 7.8 & $\begin{array}{c}\text { Traffic } \\
\text { noise }\end{array}$ \\
\hline \multirow{5}{*}{2} & B1 & 61.15 & 1.18 & 0.74 & 9.3 & $\begin{array}{l}\text { Bird song, } \\
\text { human } \\
\text { sound }\end{array}$ \\
\hline & D3 & 57.24 & 2.97 & 0.3 & 9.6 & $\begin{array}{c}\text { A little } \\
\text { background } \\
\text { music, bird } \\
\text { song }\end{array}$ \\
\hline & B2 & 54.88 & 1.77 & 0.33 & 7.4 & $\begin{array}{l}\text { Background } \\
\text { music, } \\
\text { wind sound }\end{array}$ \\
\hline & B3 & 57.79 & 2.9 & 0.02 & 10.4 & $\begin{array}{c}\text { Music, bird } \\
\text { song }\end{array}$ \\
\hline & D2 & 56.69 & 2.53 & 0.48 & 8.9 & $\begin{array}{c}\text { Wind } \\
\text { sound, } \\
\text { footpath }\end{array}$ \\
\hline 3 & D1 & 61.01 & 2.06 & 0.34 & 10.6 & $\begin{array}{c}\text { Human } \\
\text { noise }\end{array}$ \\
\hline
\end{tabular}

Based on TABLE 5, identification of the characteristics of each route has made it included in a particular cluster. The formation of clusters can be explained by several parameters. Sounds in cluster 1 have a low delay time $\left(\tau_{1}\right)$, so the pitch tends to be high. Besides, if viewed from the $\mathrm{D}_{\mathrm{R}}$, this cluster is relatively more monotonous compared to the others. While cluster 2 and cluster 3 have a longer delay time $\left(\tau_{1}\right)$, so the pitch is lower. If viewed from the frequency content, cluster 1 dominated by traffic noises; cluster 2 is dominated by natural and human sounds, while cluster 3 is dominated by human noise. In addition to cluster analysis, comparison tests were also conducted to determine the soundscapes that most preferred by the subject based on the measurement route. The results of the scores obtained are as follows, 
TABLE 6 SCORES OF COMPARISON TEST

\begin{tabular}{cc}
\hline Route & Score \\
\hline A & -0.75 \\
B & 1.67 \\
D & 5.83 \\
\hline
\end{tabular}

Based on TABLE 6, comparison tests conducted on 30 respondents showed the type of soundscapes that respondents liked the most based the individual perspective was route D. As stated in TABLE 5, this route is a member of cluster 3 with characteristics dominated by natural sounds namely the wind and chirping of birds.

\section{CONCLUSION}

Soundscapes in Joyoboyo Forest can be classified into 3 groups that have a character based on their dominance. These groups consist of dominant groups of traffic sounds, natural sounds, and human sounds. The dominance of the sound of traffic occurs on route A that is measure in session I, session II, and session III. The dominance of human and natural sounds occurs on route B in session I, session II, and session III and route D in session II and session III.

The dominance of human sounds occurs on route D that is measured in session I. The acoustic environment most preferred of respondents is route $\mathrm{D}$ with a score of 5.83 , while scores of routes $\mathrm{A}$ and $\mathrm{B}$ are respectively -0.75 and 1.67. The results of the soundscapes identification on Route D show the dominance of natural sounds (wind and bird chirps) expressed by $\mathrm{L}_{\mathrm{eq}}=57.24 \mathrm{dBA}, \mathrm{L}_{10}=59.13$ $\mathrm{dBA}, \mathrm{L}_{93}=54.52 \mathrm{dBA}, \mathrm{L}_{\max }=63.41 \mathrm{dBA}, \tau_{1}=2.97 \mathrm{~s}$, and $\Phi_{1}=0.3 \mathrm{D}_{\mathrm{R}}=9.6$. The identification using a spectrogram also shows the dominance of wind and birds singing on this route.

\section{ACKNOWLEDGMENTS}

Acoustic Instrumentation Laboratory, Department of Physics, Institut Teknologi Sepuluh Nopember. The City Government of Kediri in particular, the Department of Environment for Landscape Cleaning and Gardening which has given research permission in the Joyoboyo Urban Forest

\section{REFERENCES}

[1] P. N. Breysse and P. S. Less, Noise, New York: John Hopkin's University, 2006.

[2] R. P. Timang, V. R. Danes and F. Lintong, "The relationship of noise to the hearing function of a machine worker," $e$-Biomedik, vol. 4 , no. 1, pp. 1-5, 2016.

[3] Bennet and Brigitte, "The Soundscape Standart," INTERNOISE, Hamburg, 2016.

[4] J. Budel, "Creative Response to Soundscape Ecology: Innovative Framework and Case Study," Brisbane, 2016.

[5] Y. Soeta and R. Shimokura, "Sound quality evaluation of airconditioner based on factor on the autocorrelation function," Applied Acoustic, no. 124, pp. 11-19, 2017.

[6] Z. Deng, A. Liu, and J. Kang, "Linear Multivariate Evaluation Models for Spatial Perception," Acoustical Society of America, pp. 2860-2870, 2015.

[7] S. D. Snyder, Active Noise Control Primer, New York: Springer, 2000.

[8] P. Jennings and R.Cain, "A framework for improving urban soundscapes," Applied Sound, no. 74, pp. 293-299, 2013.

[9] Bruel and Kjaer, Environmental Noise, Denmark: Bruel\&Kjaer Sound and Vibration Measurement, 2000. 